\title{
Epigenetic Approaches to the Treatment of Renal Cell Cancer
}

\author{
Seong Hwi Hong ${ }^{1}$, Jiyoung Lee ${ }^{1}$, Eun Bi Jang ${ }^{1,2}$, Sung Yul Park', \\ Hong-Sang Moon ${ }^{1}$, Young Eun Yoon ${ }^{1}$ \\ ${ }^{1}$ Department of Urology, Hanyang University College of Medicine, Seoul, Korea \\ ${ }^{2}$ Department of Translational Medicine, Hanyang University Graduate School for Biomedical Science \& \\ Engineering, Seoul, Korea
}

To summarize the epigenetics in renal cell carcinoma (RCC) and discuss the potential use of epigenetic modifiers as RCC biomarkers and treatments. Pertinent articles available on PubMed and google scholar database pertaining to kidney cancer and epigenetics were reviewed. Metastatic RCC is one of the most difficult cancers to treat. Although RCC is commonly known to be caused by VHL mutations, it is not enough to understand the complete pathophysiology of RCC. Epigenetic factors can play a fundamental role in the pathogenesis of RCC. Epigenetic regulators are classified as epigenetic writers, readers, and erasers according to their role. In this review, we discuss the potential role of epigenetic regulators as a biomarker for RCC. We also review medications that target epigenetic enzymes and are currently tried in RCC therapy. (Korean J Urol Oncol 2020;18:78-90)

Key Words: Epigenetics $\cdot$ Kidney cancer

\section{INTRODUCTION}

Kidney cancer accounts for $2 \%-3 \%$ of all cancers worldwide. Renal cell carcinoma (RCC) is the most prevalent subtype of kidney cancer, accounting for approximately $90 \%$ of all cases, ${ }^{1}$ and is a heterogeneous disease with nearly 20 subtypes. The most prevalent subtype is clear cell (cc)RCC (75\%), followed by papillary (p)RCC (10\%) and chromophobe (ch)RCC $(5 \%)^{2}$; as a result, RCC research is

Received November 28, 2019, Revised January 2, 2020,

Accepted January 3, 2020

Corresponding Author: Young Eun Yoon

Department of Urology, Hanyang University College of Medicine,

222 Wangsimni-ro, Seongdong-gu, Seoul 04763, Korea

E-mail: urologistyoon@gmail.com

Tel: +82-2-2290-8593, Fax: +82-2-2299-2186

ORCID: https://orcid.org/0000-0001-8059-6649

- This research was supported by Basic Science Research Program through the National Research Foundation of Korea (NRF) funded by the Ministry of Education (2018R1D1A1B07051225). mostly limited to ccRCC. The most common genetic event of ccRCC is the inactivation of the von Hippel-Lindau $(V H L)$ tumor suppressor gene, ${ }^{3}$ which induces the stabilization of HIF1a and HIF2a to increase transcription of the hypoxia response genes $V E G F$ and $P D G F$ and leads to angiogenesis. ${ }^{4}$ pRCC is further classified by genotype: type 1 pRCC occurs due to a mutation in the $c$-Met protooncogene, which encodes a tyrosine kinase, and type 2 pRCC is associated with mutations in the gene encoding fumarate hydratase. ${ }^{5}$ In other RCC subtypes, the involvement of VHL and c-Met are unclear. Therefore, these targets alone are insufficient for treating all forms of RCC, highlighting the critical need to identify novel therapeutic targets relevant to several subtypes of RCC. In this review, we will summarize the epigenetics in RCC and discuss the potential use of epigenetic modifiers as RCC biomarkers.

(i) (8) This is an Open Access article distributed under the terms of the Creative Commons Attribution Non-Commercial License (http://creativecommons.org/licenses/by-nc/4.0/) which permits unrestricted non-commercial use, distribution, and reproduction in any medium, provided the original work is properly cited. 2020 (C) Copyright The Korean Urological Oncology Society and The Korean Prostate Society. All Rights Reserved. 


\section{EPIGENETIC REGULATION}

Regulation of gene expression and activity is an essential process for cell survival and adaptation amidst various environmental conditions. Chromatin structure must be correctly regulated by epigenetic regulators for appropriate gene expression. These regulators are classified as epigenetic writers, readers, and erasers according to their role. Epigenetic writers are enzymes that add functional groups (epigenetic marks) to DNA and histones that are recognized by epigenetic readers. Most epigenetic marks are reversible by action of epigenetic erasers, which can remove the marks and reverse its effects. Writers and erasers can contain reader domains that allowing a 'reading-writing' or 'readingerasing' process. The interaction system of the 3 epigenetic regulators controls gene transcription, and numerous reports have demonstrated that defects of this system induce the initiation and progression of several cancers, including RCC.,

\section{EPIGENETIC WRITERS IN RCC}

Epigenetic writers enable several epigenetic modifications, including methylation, acetylation, phosphorylation, and ubiquitination. This review will focus on methylation and acetylation, which are the most widely studied modifications among epigenetic marks. Both DNA and histone proteins are liable to methylation, while acetylation is restricted to histones. ${ }^{8}$ These 2 modifications regulate cellular gene expression patterns by cycling between activation or suppression of transcription. Here, we describe 3 epigenetic writers: DNA methyltransferases (DNMTs), histone methyltransferases (HMTs), and histone acetyltransferase (HATs).

\section{DNA Methyltransferases}

DNA methylation is a process during which methyl groups bind to DNA to affect gene expression without changing DNA sequences. This modification most often involves the covalent binding of methyl to the 5'-carbon of cytosine residues. In mammals, the DNMT family of enzymes, which mediates DNA methylation, consists of DNMT1, DNMT2, DNMT3A, DNMT3B, and DNMT3L. Maintenance of DNA methylation during DNA replication is accomplished by DNMT1, whereas de novo DNA meth- ylation is catalyzed by DNMT3A and DNMT3B. DNA methylation can occur in promoters, intergenic regions, gene bodies, and enhancers. Promoter methylation typically leads to transcriptional repression and is usually associated with $\mathrm{CpG}$ dinucleotides. The importance of gene body methylation has been unestablished but is generally associated with a permissive transcriptional state. Although both DNMT3A and DNMT3B participate in de novo DNA methylation, but their target regions are different. ${ }^{9,10}$ DNMT3A primarily methylates promoters and enhancers, whereas DNMT3B is associated with actively transcribed genomic loci.

Several studies have shown that abnormal DNA methylation occurs in RCC. For example, hypermethylation of tumor suppressor genes by abnormally high expression of DNMT or hypo-methylation of oncogenes due to low levels of DNMT may contribute to the generation, development, and progression of ccRCC. ${ }^{11}$ In addition, the hypermethylation of $K L F 5$, an epidermal growth factor response element, by DNMT1 is strongly associated with a poor prognosis in ccRCC patients. ${ }^{12}$ While DNMT1 plays an oncogenic role in RCC, DNMT3A exhibits tumor suppressive role. HIF $2 a$, an important gene in ccRCC, is silenced via methylation by DNMT3A, which limits the proliferation capacity of cells under hypoxic conditions. ${ }^{13}$

\section{Histone Methyltransferases}

The methylation of histone lysine residues can be widespread and can result in various transcriptional effects, depending on the extend and position of the modifications. Lysine is modified with one or more methyl groups (mono-, di-, and trimethyl) at various positions. Methylation of $\mathrm{H} 3 \mathrm{~K} 4, \mathrm{H} 3 \mathrm{~K} 36$, and H3K79 is considered an active chromatin mark, whereas H3K9, H3K27, and H4K20 methylation are associated with transcriptional repression. However, methylation of H3K4 usually occurs with trimethyl marks found in active promoters, whereas monomethyl marks target active enhancers. ${ }^{14}$

In general, methyl marks are enzymatically added to histone lysine residues by lysine methyltransferases (KMT), a group of highly specific enzymes that target lysine residues with a defined number of methyl groups, leading to corresponding transcriptional effects (Table 1). For example, enzymes KMT1A (SUV39H1) and KMT1B (SUV39H2) con- 
vert only $\mathrm{H} 3 \mathrm{~K} 9 \mathrm{me} 1$ to $\mathrm{H} 3 \mathrm{~K} 9 \mathrm{me} 3$, while the related enzyme KMT1C (G9a) generates only H3K9me2. KMT1C has been suggested as a potential therapeutic target for ccRCC because it catalyzes the methylation of $\mathrm{H} 3 \mathrm{~K} 9$ to negatively regulate essential tumor suppressors during hypoxia. ${ }^{15}$ KMT4 (DOT1L) is the only enzyme involved in the methylation of H3K79 and can lead to mono-, di-, or trimethyl conversion. Methylation by KMT4 is important in a variety of biological processes, including telomere maintenance and cell cycle regulation. Notably, higher KMT4 expression in

Table 1. Lysine methyltransferases and their associated substrates and effects on chromatin

\begin{tabular}{lll}
\hline \multicolumn{1}{c}{ Enzyme } & Substrate & Active/repressive \\
\hline KMT2A (MLL1) & H3K4 & Active chromatin \\
KMT2B (MLL2) & H3K4 & \\
KMT2C (MLL3) & H3K4 & \\
KMT2D (MLL4) & H3K4 & \\
KMT2E (MLL5) & H3K4 & \\
KMT2F (SET1A) & H3K4 & \\
KMT2G (SET1B) & H3K4 & \\
KMT2H (ASH1L) & H3K4 & \\
KMT3D (SMYD1) & H3K4 & \\
KMT3E (SMYD3) & H3K4 & \\
PRDM9 & H3K4 & \\
KMT7 (SETD7) & H3K4 & \\
NSD3 (WHSCL1) & H3K4 & \\
SUV39H1 (KMT1A) & H3K9 & Active chromatin \\
SUB39H2 (KMT1B) & H3K9 & \\
KMT1C (G9a/EHMT2) & H3K9 & \\
KMT1D & H3K9 & \\
(EuHMTase/GLP/EHMT1) & & \\
KMT1E (ESET/SERDB1) & H3K9 & \\
KMT1F (CLL8, SETB2) & H3K9 & \\
KMT8 (PRDM2) & H3K9 & \\
KMT6A (EZH2) & H3K27 & Repressive chromatin \\
KMT6B (EZH1) & H3K27 & \\
NSD2(WHSC1) & H3K27 & \\
NSD3(WHSCL1) & H3K27 & \\
SETD3 & H3K27 & \\
KMT3A (SETD2) & H3K36 & Active chromatin \\
KMT3B (NSD1) & H3K36 & \\
KMT3C (SMYD2) & H3K36 & \\
KMT4 (DOT1L) & H3K79 & Active chromatin \\
KMT5A (SETD8) & H4K20 & Repressive chromatin \\
KMT5B(SUV4-20H1) & H4K20 & \\
KMT5C (SUV4-20H2) & H4K20 & \\
\hline
\end{tabular}

ccRCC patients has been associated with poor clinical outcomes. ${ }^{16}$ Analysis of ccRCC-related data from The Cancer Genome Atlas revealed a relevant somatic mutation of SETD2, which normally methylates H3K36 and acts as a tumor suppressor. DNA hypo-methylation resulting from the loss of SETD2 is associated with ccRCC oncogenesis. ${ }^{17}$ However, another study reported that SETD2 expression itself, without H3K36 methylation, is related to the aggressiveness of ccRCC. ${ }^{18}$ Through tissue screening of global methylated $\mathrm{H} 3 \mathrm{~K}$ among ccRCC patients, mRNA expression levels of 4 HMTs (MLL1, MLL2, SMYD2, and NSD2) were significantly increased compared to normal renal cells. ${ }^{19}$ EZH2, which catalyzes methylation of H3K27, is highly expressed in RCCs, contributes to short survival

Table 2. Lysine methyltransferases and their associated substrates

\begin{tabular}{|c|c|c|}
\hline Family & Enzyme & Substrate \\
\hline \multirow[t]{2}{*}{ GNAT } & KAT2A (GCN5) & $\begin{array}{l}\text { H3К9, H3К14, H3К56, } \\
\text { H4K5, H4K8, H4K12, } \\
\text { H4K16, H4K91, H3K9, } \\
\text { H3K14 }\end{array}$ \\
\hline & KAT2B (PCAF) & H3К9, Н3К14 \\
\hline \multirow[t]{2}{*}{ P300/CBP } & KAT3A (CBP) & $\begin{array}{l}\text { H3К9, Н3К14, Н3К56, } \\
\text { H4K5, H4K8, H4K12, } \\
\text { H4K16, H4K91 }\end{array}$ \\
\hline & KAT3B (P300) & $\begin{array}{c}\text { H3К14, H3К18, Н3К27, } \\
\text { H3K56, H4K5, H4K8, } \\
\text { H4K12, H4K16, H3K14 }\end{array}$ \\
\hline \multirow[t]{6}{*}{ MYST } & KAT4 (TAF1) & H3K14 \\
\hline & KAT5 (TIP60) & $\begin{array}{l}\text { H2AK5, H4K5, H4K8, } \\
\text { H4K12, H4K16 }\end{array}$ \\
\hline & KAT6A (MYST3) & Н3К9, Н3К14 \\
\hline & KAT6B (MYST4) & $\begin{array}{l}\text { H4K5, H4K8, H4K12, } \\
\text { H4K16 }\end{array}$ \\
\hline & KAT7 (MYST2) & $\begin{array}{l}\text { H3K14, H4K5, H4K8, } \\
\text { H4K12 }\end{array}$ \\
\hline & KAT8 (MYST1) & H4K16 \\
\hline- & KAT1 (HAT1) & H2AK5, H4K5, H4K12 \\
\hline- & KAT9 (ELP3) & H3К9, Н3К 18 \\
\hline- & KAT12 (GTF3C4) & H3K14 \\
\hline- & KAT13A (NCOA1) & H3K14 \\
\hline- & KAT13B (NCOA3) & H3K14 \\
\hline- & KAT13D (CLOCK) & H3K14 \\
\hline- & MGE15 & H4K8, H3К14 \\
\hline- & NAT10 & - \\
\hline- & CDY1 & - \\
\hline- & CDY2 (CDY2A) & - \\
\hline- & CDYL & - \\
\hline
\end{tabular}


times in these patients, and is a rational target for RCCs that are resistant to sunitinib, a common ccRCC chemotherapeutic. $^{20,21}$

\section{Histone Acetyltransferases}

Lysine acetylation induces decompaction of chromatin, providing access for transcription factors to increase gene expression. Acetylation marks and HATs are mainly found in association with active promoters and enhancers. ${ }^{22}$ Numerous lysine residues in the tails of histones H2A, H2B, $\mathrm{H} 3$, and $\mathrm{H} 4$ can be acetylated, and these modifications play an important role in DNA repair and replication, as well as in transcription. ${ }^{23,24}$

Histone acetyltransferases, also known as lysine acetyltransferases (KATs), are grouped based on their amino acid sequence, with the GNAT, MYST, and p300/CBP families being most characteristic (Table 2). The GNAT family consists of KAT2A (GCN5) and KAT2B (PCAF), which are coactivators for various transcription factors. In mammals, the MYST family includes 5 enzymes (KAT8 [MYST1], KAT7 [MYST2], KAT6A [MYST3], KAT6B [MYST4], and KAT5 [TIP60]) with the MYST domain that are directly involved in protein proliferation, differentiation, and apoptosis. $^{25}$ The CBP/P300 family comprises CBP and

Table 3. Clinical trial status of epigenetics-based therapeutic agents in renal cell carcinoma

\begin{tabular}{|c|c|c|c|c|c|}
\hline Enzymatic class & Drug & Combined therapy & Trial phase & Status & $\begin{array}{l}\text { Reference/clinical trial } \\
\text { identification }\end{array}$ \\
\hline \multirow[t]{7}{*}{ DNMT inhibitor } & Decitabine & Oxaliplatin & Phase 2 & Recruiting & NCT04049344 \\
\hline & & High-dose IL-2 & Phase 1 & Completed & [Ref 32] \\
\hline & & Interferon- $\alpha 2 b$ & Phase 2 & Terminated & NCT00561912 \\
\hline & Azacitidine & Interferon- $\alpha 2 b$ & Phase 1 & Completed & NCT00217542 \\
\hline & & Bevacizumab & Phase $1 / 2$ & Terminated & NCT00934440 \\
\hline & Guadecitabine & - & Phase 2 & Recruiting & NCT03165721 \\
\hline & MG98 & - & Phase 2 & Completed & [Ref 33] \\
\hline EZH2 inhibitor & Tazemetostat & - & Phase 2 & Recruiting & NCT02601950 \\
\hline \multirow[t]{2}{*}{ BET inhibitor } & TEN-010 & - & Phase 1 & Completed & NCT01987362 \\
\hline & BMS-986158 & - & Phase $1 / 2$ & Recruiting & NCT02419417 \\
\hline \multirow[t]{17}{*}{ HDAC inhibitor } & Vorinostat & - & Phase 2 & Completed & NCT00278395 \\
\hline & & Isotretinoin & Phase $1 / 2$ & Terminated & NCT00324740 \\
\hline & & Pembrodizumab & Phase 1 & Recruiting & NCT02619253 \\
\hline & & Bevacizumab & Phase $1 / 2$ & Completed & NCT00324870 \\
\hline & & Sorafenib & Phase 1 & Completed & [Ref 95] \\
\hline & & Ridaforolimus & Phase 1 & Completed & [Ref 96] \\
\hline & Panobinostat & - & Phase 2 & Completed & NCT00550277 \\
\hline & & Everolimus & Phase $1 / 2$ & Terminated & NCT01582009 \\
\hline & & Sorafenib & Phase 1 & Completed & NCT01005797 \\
\hline & Romidepsin & - & Phase 1 & Ongoing & NCT01638533 \\
\hline & & - & Phase 2 & Completed & NCT00106613 \\
\hline & Entinostat & Ipilimumab & Phase 2 & Recruiting & NCT03552380 \\
\hline & & Nivolumab & Phase 2 & Recruiting & NCT03552380 \\
\hline & & Isotretinoin & Phase 1 & Completed & [Ref 97] \\
\hline & & IL-2 & Phase $1 / 2$ & Ongoing & NCT01038778 \\
\hline & & Atezolizumab & Phase $1 / 2$ & Recruiting & NCT03024437 \\
\hline & AR-42 & Pazopanib & Phase 1 & Terminated & NCT02795819 \\
\hline
\end{tabular}

DNMT: DNA methyltransferases, EZH2: enhancer of zeste homolog 2, BET: bromodomains and extraterminal, HDAC: histone deacetylases, IL: interleukin. 
KAT3B (P300), enzymes with catalytic domains and bromodomains that also act as coactivators. ${ }^{26}$ In ccRCC, overexpression of $\mathrm{CBP}$ not only induces carcinogenesis ${ }^{27}$ but also plays an important role in the transcriptional activation of the G250MN protein, an isoenzyme of the carbonic anhydrase family, which is involved in increased expression of HIF1a in ccRCC. ${ }^{28}$

\section{Epigenetic Therapy: Targeting Writer in RCC}

Many studies evaluating the therapeutic benefits of drug targeting epigenetic writer are underway (Table 3, Fig. 1). For example, decitabine (5-AZA-2'-deoxycytidine) is a representative DNMTi that inhibits cell growth and NF-kB signaling in various cancers, including RCCs. ${ }^{29,30}$ The dinucleotide of decitabine, guadecitabine, exhibits improved absorption capacity for DNA of rapidly dividing tumor cells, leading to improved efficacy. ${ }^{31}$ Both of these drugs are currently in a clinical trial for their activity against RCCs (NCT04049344, ${ }^{32}$ NCT00561912, NCT03165721). Azaciti- dine, another drug currently in clinical trials, is coadministered with interferon- $\alpha 2 \mathrm{~b}$ or bevacizumab (NCT00217542 and NCT00934440, respectively), while MG98 is being evaluated in a phase II clinical trial as a monotherapy for RCCs. ${ }^{33}$

Although the development of HMTi has not advanced as far as that of other therapies, increasing evidence indicates that HMT is an important druggable target for cancer therapy. In RCCs, the use of HMTi leads to potent antitumorigenic effects. ${ }^{34-37}$ Specifically, the EZH2 inhibitor tazemetostat is in a phase II clinical trial as a monotherapy for RCC (NCT02601950). Numerous studies of HATi have been performed, such as P300 inhibitor, ${ }^{38,39}$ but no clinical trials are currently underway in RCCs.

\section{EPIGENETIC READERS IN RCC}

Various histone and DNA modifications suggested by epigenetic writers are recognized by epigenetic readers, which

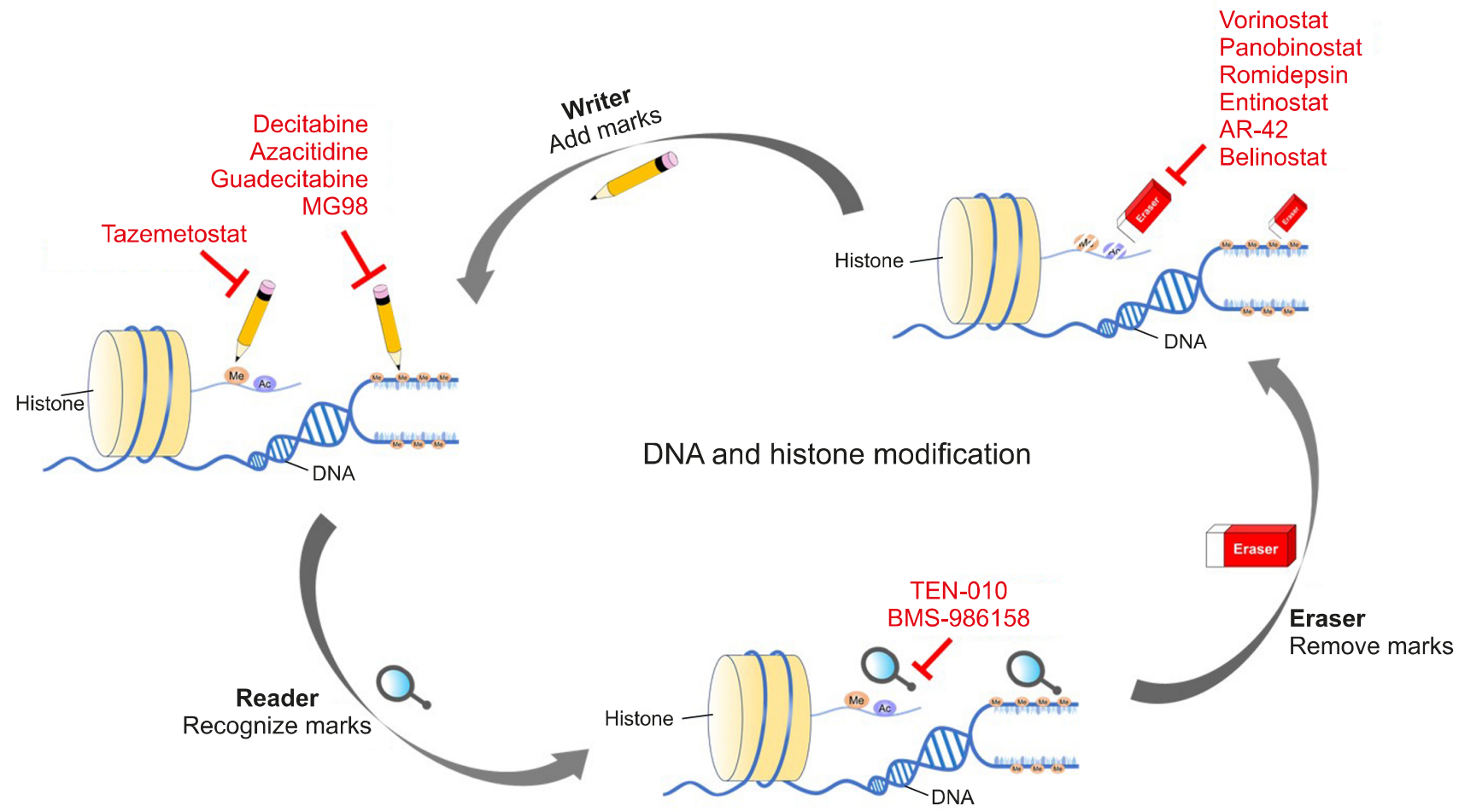

Me Methyl group

Ac Acetyl group

Fig. 1. Graphical abstract for DNA and histone modification. This figure shows the regulatory mechanisms of DNA and histones by the epigenetic writer, reader, and eraser, as well as a list of inhibitors for each enzyme used in renal cell carcinoma therapy. 
contain specialized domains that identify and bind to these modifications. We will focus on protein domains that can recognize methylated DNA and methylated or acetylated histones, the 2 most widely studied histone modifications.

\section{DNA Methylation Readers}

Methyl-CpG binding domain (MBD) proteins recognize and bind to methylated DNA to recruit factors for chromatin silencing. These proteins are classified into 3 groups according to domains: MBD, ZnF, and SRA (SET and RING finger-associated) families (Fig. 2). The MBD family includes MeCP2 and proteins MBD1-6; MeCP2. Among them, MBD1 and MBD2 bind to methylated DNA and interact with various inhibitory complexes through their transcriptional repressive domain (TRD) to silence the bound loci. MBD3 and MBD4, which do not contain a TRD, cannot bind to methylated DNA, although MBD4 enhances DNA repair through glycosylase activation. ${ }^{40}$ Because MBD is rarely reported in RCC, further research on its possible role in carcinogenesis is needed.

Eight proteins (Kaiso, ZBTB4, ZBTB38, ZFP57, KLF4, EGR1, WT1, CTCF) with a ZnF motif compose the ZnF family. Kaiso, ZBTB4, and ZBTB38, the most well-studied proteins in this family, bind to methylated $\mathrm{DNA}^{41}$ and are known to repress transcription in a DNA methylation-dependent-manner. However, a recent study suggested that some proteins containing the $\mathrm{ZnF}$ motif initially bind to unmethylated regions. ZFP57 is essential for the recognition of methylated hexanucleotides (TGCCGC) in the imprinting

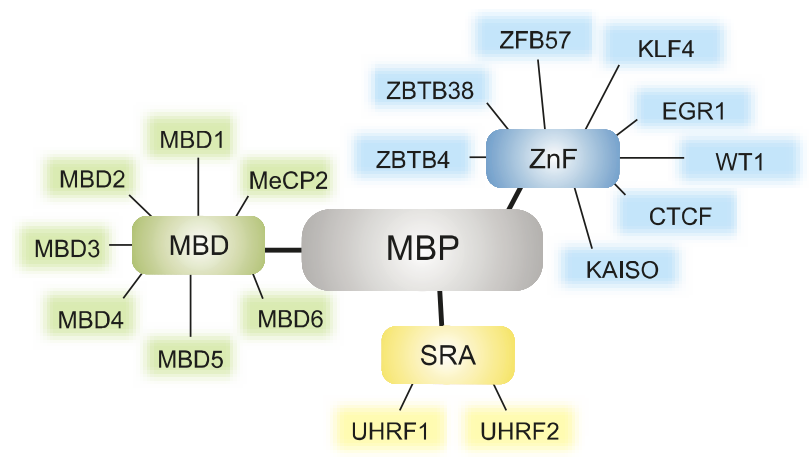

Fig. 2. Methyl-CpG binding domain proteins (MBPs). These epigenetic readers are classified as into $\mathrm{MBD}, \mathrm{ZnF}$, or SRA families based on the presence of specific binding motifs. MBD: methyl-CpG binding domain, $\mathrm{ZnF}$ : zinc finger, SRA: SET and RING finger-associated. control region and for protecting DNA methylation imprints during early embryogenesis in mammals. ${ }^{42}$

The SRA domain proteins consist of UHRF1 (ubiquitinlike with plant homeodomain [PHD] and RING finger-domain 1) and UHRF2. UHRF1 recognizes hemi-methylated DNA and recruits DNMT1. ${ }^{43}$ Although UHRF2 has an amino acid sequence similar to that of UHRF1, UHRF2 functions differently to maintain methylation and primarily recognizes $5 \mathrm{hmc}$ and $5 \mathrm{mc} .^{44}$ UHRF1, which is overexpressed in most cancers, has been proposed as a universal oncogenic biomarker; in ccRCC, UHRF1 inhibits p53-mediated cell apoptosis by inactivating $\mathrm{p} 53 .{ }^{45}$

\section{Histone Methylation Readers}

Methylated histone lysine residues are recognized by several domains: Ankyrin, ADD (ATRX-Dnmt3-Dnmt3L), bromo-adjacent homolog, chromo-barrel, chromodomain, double chromodomain, malignant brain tumor, PHD, ProlineThreonine-Proline-Threonine (PWWP), tandem Tudor domain, and $\mathrm{WD}^{4} 0^{46}$ (Fig. 3). Each domain is highly specific and recognizes lysines in a particular methylation state. For example, the PHD finger interacts with $\mathrm{H} 3 \mathrm{~K} 4 \mathrm{me} 3$, an active promoter mark, whereas the WD40 domain binds to various trimethylated lysines related to repressive marks, and the ADD domain of ATRX recognizes H3K9me3 only when H3K4me 2 and H3K4me 3 are absent. The specificity of these domains is controlled by interactions with amino acids near the modified lysine and the structure of the binding pocket. In RCC, ankyrin repeat and single $\mathrm{KH}$ domain 1

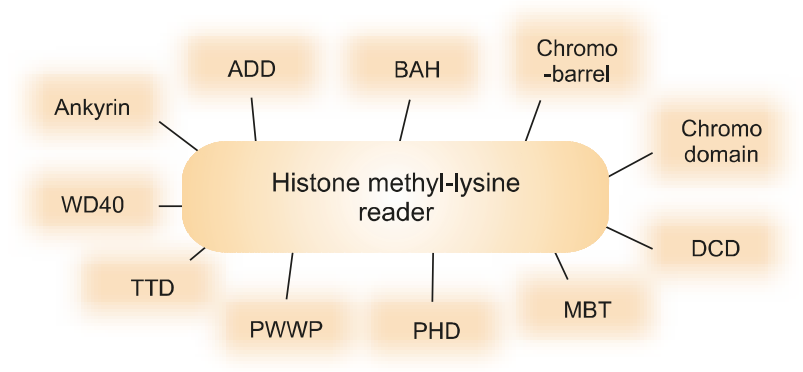

Fig. 3. Histone methylation readers. Proteins that recognize methylated histone lysine residues contain diverse recognition domains as indicated by the outer boxes. ADD: ATRX-Dnmt3Dnmt3L, BAH: bromo-adjacent homolog, TTD: tandem tudor domain, PWWP: Proline-Threonine-Proline-Threonine, PHD: plant homeodomain, MBT: malignant brain tumor, DCD: double chromodomain. 
was significantly increased compared to normal renal cells and was essential for controlling cell proliferation in ccRCC through interaction with 3 tumor-suppressive miRNAs (miR29a, miR-205, and miR-196a). ${ }^{47}$ Nuclear expression of PHD finger 2 in ccRCC is also greatly increased, suggesting that epigenetic control of lipid synthesis via CEBPa is important. ${ }^{48}$

\section{Histone Acetylation Readers}

The decompaction of chromatin induced by histone acetylation is specifically recognized by the bromodomain and tandem PHD domains. However, the specificity of these domains is lower than that of methylation readers. Bromodomains predominate in studies of histone acetylation readers because bromodomains were the only known acetylation reader until 2008, when the PHD domain was discovered. ${ }^{49}$ Approximately 60 types of proteins with broad functions in humans contain bromodomains. ${ }^{50}$ For example, Bromodomains and Extraterminal (BET) family proteins, which contain 2 bromodomains, include the readers BRD2, BRD3, BRD4, and BRDT. Among these, BRD4 is highly expressed in various cancers and is considered an oncogene ${ }^{51}$; for example, upregulated BRD4 in RCC plays a critical role in RCCs progression (Fig. 4). ${ }^{52}$ In support of this relationship, the combined chemical inhibition of BRD4 and PI3K-AKT pathway components via SF2523 can effectively block ccRCC growth. $^{53}$

\section{Epigenetic Therapy: Targeting Reader in RCC}

The treatment of RCC by targeting DNA and histone methylation readers has been rarely studied, whereas the research on BETs, histone acetylation reader, has been ac- tively performed. Although the study of JQ1, which is one of the famous BET inhibitors, has been conducted by many study groups, JQ1 is known to not only have a short halflife but also the concentration required when used in monotherapy exceeds the physiological safety level. ${ }^{54}$ As new BET inhibitors, TET-010 and BMS086158 are currently being evaluated in clinical trials (NCT01987362 and NCT024 19417) (Table 3, Fig. 1). However, because drugs targeting epigenetic readers are relatively less researched than other enzymes, more research on readers will be needed.

\section{EPIGENETIC ERASERS IN RCC}

Epigenetic marks are not permanent, which allows the cell to adapt to environmental changes. For the chromatin to react rapidly, the expression state of the locus must be modified. To accomplish this rapid conversion, epigenetic erasers remove epigenetic marks generated by the writer. Here, we discuss the reversibility of DNA methylation, histone methylation, and histone acetylation via epigenetic erasers.

\section{DNA Demethylases}

The demethylation of mammalian DNA occurs either passively via absence of DNMT or actively via catalysis of the TET enzyme family. ${ }^{55}$ In the absence of DNMT, methylated cytosine is repeatedly removed during DNA replication. Active DNA demethylation is catalyzed by TET family enzymes, which include TET1, TET2, and TET3. The core catalytic domain of these proteins consists of a cystine-rich domain, a double-stranded $\beta$-helix domain, and a Fe(II)-in-

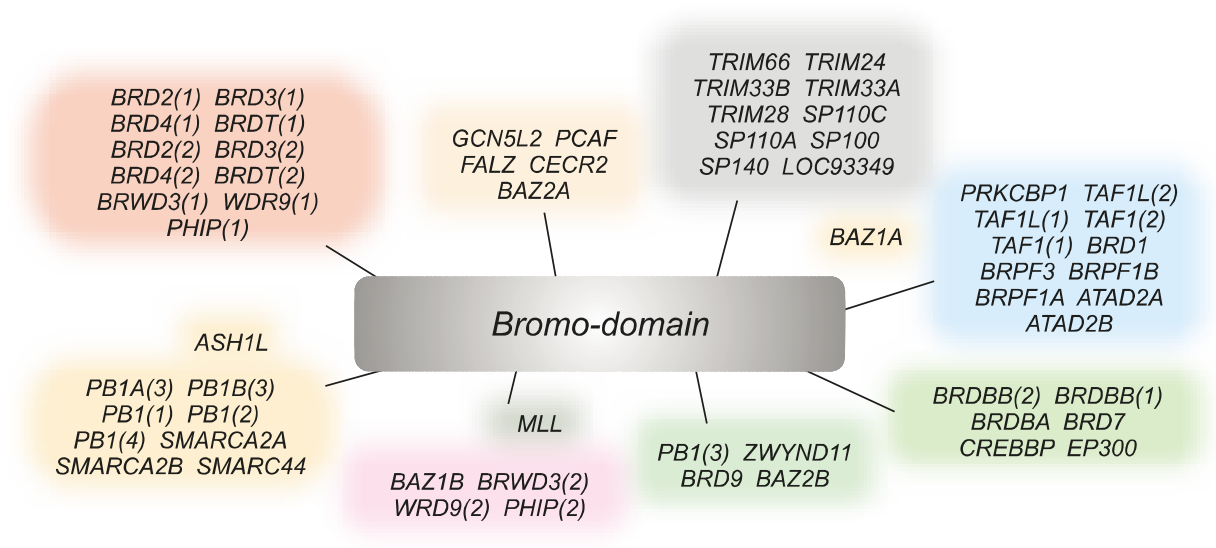

Fig. 4. Bromodomains. Proteins recognize histone acetylation via bromodomains and tandem plant homeodomains. 


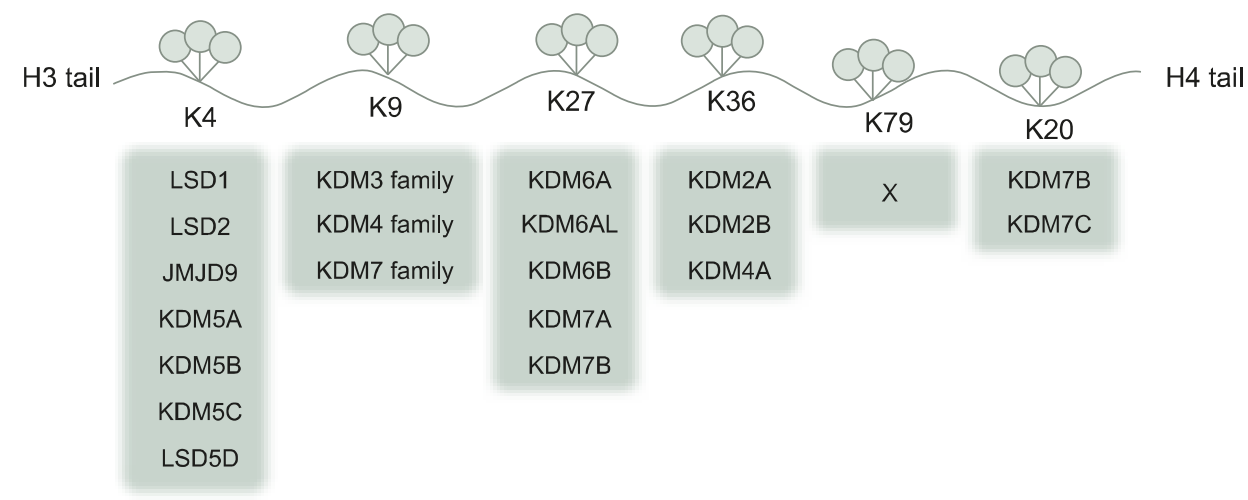

Fig. 5. Histone demethylases. These epigenetic erasers are classified based on their enzymatic mechanisms and act at specific sites within chromatin based on position and number of methyl groups present. teracting $\mathrm{HxD}$ motif and is highly conserved in the carboxy-terminus. ${ }^{56}$ TET1 and TET3 have an additional CXXC domain with 2 Cys4-type zinc finger motifs in their amino terminals to promote DNA binding. ${ }^{57,58}$ TET1 clears the imprinting mark in primordial germ cells, whereas in RCCs, the miR124-mediated silencing of TET1 leads to increased MEG3 expression, cell proliferation, and tumor growth. ${ }^{59}$ TET2 plays an important role in hematopoiesis, and mutations in TET2 result in hematopoietic malignancies. ${ }^{60,61}$ Moreover, TET2 is mutated in RCCs, leading to sunitinib resistance during immunotherapy. ${ }^{62}$ Although TET3 constitutively participates in zygotic paternal DNA reprogramming, ${ }^{63}$ TET3 is one of 8 significantly upregulated genes in 55 primary ccRCC tumors and affects patient survival rates. $^{56}$

\section{Histone Demethylases}

Numerous histone lysine demethylases (KDMs) remove methyl groups from lysine residues (Fig. 5). These KDMs are classified as LSD and JMJC proteins by their enzymatic mechanisms. The LSD group consists of KDM1A (LSD1) and KDM1B (LSD2). LSD1 specifically removes monoand dimethylation of $\mathrm{H} 3 \mathrm{~K} 4$ and $\mathrm{H} 3 \mathrm{~K} 9$ lysines to generate formaldehyde via methyl group oxidation. ${ }^{64}$ LSD2 also demethylates mono- and dimethylated lysines of H3K4 and may act as a maternal imprinting factor in oocytes, as well as an activator of NF-kB. ${ }^{65,66}$ In RCC, H3K4 pattern analysis determined that LSD2, but not LSD1, is highly expressed and that LSD2 inhibition led to suppressed cell viability and eventual apoptosis. Accordingly, LSD2 has been proposed as a new prognostic marker for RCC. ${ }^{19}$

The JMJC family includes approximately 20 lysine-specific demethylases. Unlike LSD proteins, JMJC enzymes

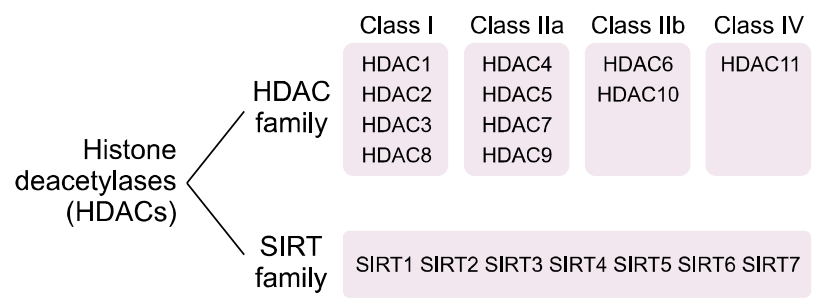

Fig. 6. Histone deacetylases. The acetylation of histone lysine residues is reversed by multiple classes of epigenetic erasers with specific recognition sites with chromatin. SIRT: selective internal radiation therapy.

can eliminate trimethylation. ${ }^{67}$ Representative JMJC members include KDM2, KDM3, KDM4, KDM5, KDM6, KDM7, and KDM8. Although several histone methyl marks (e.g., H3K79) have not yet been correlated with a specific demethylase, ${ }^{68}$ some KDMs are reported to play an important role in RCCs. ${ }^{69}$ For example, KDM3A, a demethylase of $\mathrm{H} 3 \mathrm{~K} 9 \mathrm{me} 1 / 2$ involved in the development of several cancers $^{70,71}$ is highly expressed during hypoxic conditions, is associated with increased HIF1a, and contributes to RCC development and progression via the hypoxia-mediated angiogenesis pathway. ${ }^{63} \mathrm{KDM} 5 \mathrm{C}$ demethylates $\mathrm{H} 3 \mathrm{~K} 4 \mathrm{me} 1 / 2$, and its altered expression affects breast cancer development. $^{72}$ A systemic sequencing study of ccRCC reported mutations of KDM5C in approximately 4\% of the 132 ccRCC cases, ${ }^{73,74}$ KDM6A and KDM6B demethylases target $\mathrm{H} 3 \mathrm{~K} 27 \mathrm{me} 2 / 3$, although in RCC, $K D M 6 A$ carries a somatic null mutation and $K D M 6 B$ is overexpressed, leading to oncogene-induced senescence. Thus, both KDM6A/B appear to play important, yet contrasting, roles in ccRCC development. $^{75,76}$ 


\section{Histone Deacetylases}

Acetylation of histone lysines is reversed by various histone deacetylases (HDACs), which inhibits transcription by increasing chromatin compaction. In mammals, HDACs are classified into 2 families, the HDAC family and the Sirtuins (SIRT)/class III family (Fig. 6). The HDAC family consists of 11 enzymes and is further divided into classes I, IIa, IIb, or IV based on homology. Class I HDACs include HDAC1/ $2 / 3$, which are collectively recruited and expressed at chromatin as a complex, ${ }^{40,77-80}$ whereas HDAC8 is active in isolation. ${ }^{81}$ HDAC1 and HDAC2 are essential for the growth and survival of ccRCC, as the genetic removal of $H D A C 1 / 2$ inhibits apoptosis and downregulation of the epithelial marker E-cadherin. ${ }^{82}$ HDAC3 is also overexpressed in RCCs and is involved in tumorigenesis. ${ }^{83}$

Class IIa HDACs, consisting of HDAC4, HDAC5, HDAC7, and HDAC9, also function by forming a complex but have lower catalytic activity compared to class I and IIb enzymes. ${ }^{84}$ A study in which an N-terminal spliced variant of HDAC9 repressed gene transcription confirmed that its catalytic domain is nonessential in the complex. ${ }^{85}$ In RCCs, low levels of H3K18ac and H3K27ac, induced by highly enriched HDAC7 in the OCT2 promoter, regulate drug uptake by inhibiting OCT2 transcription. ${ }^{86}$

HDAC6 and HDAC10 are class IIb enzymes with different defining domains. ${ }^{87}$ In RCCs, HDAC6 and HDAC10 are potential prognostic factors, as HDAC6 is increased and HDAC6 is decreased compared to normal kidneys. ${ }^{88,89}$ Therefore, further study is needed to determine which pathway(s) are targeted by these HDACs and their contribution to RCC development. HDAC11 is the only class IV HDAC, and while its sequence is similar to that of classes I and II HDACs, this enzyme is relatively uncharacterized. ${ }^{90}$

The SIRT/class III HDAC family includes SIRT1, SIRT2, SIRT3, SIRT4, SIRT5, SIRT6, and SIRT7, which function through $\mathrm{NAD}^{+}$-dependent mechanisms. ${ }^{91}$ Expression screening of SIRT proteins revealed that levels of SIRT1, SIRT3, and SIRT6 were significantly lower in RCCs than in normal kidneys. ${ }^{92}$ In particular, the downregulation of SIRT3 leads to increased reactive oxygen species and stabilization of HIF1a in RCC, highlighting its tumor-suppressive role in RCC, as well as in other cancers. ${ }^{93,94}$

\section{Epigenetic Therapy: Targeting Eraser in RCC}

The most commonly developed and used drugs in epigenetics-based therapy are HDAC inhibitors (HDACi) (Table 3, Fig. 1). Six additional HDACi are currently in clinical trials: vorinostat, panobinostat, romidepsin, entinostat, AR42, and belinostat. Vorinostat (SAHA) is a potent nonselective HDACi that has been studied as a monotherapy for RCCs (NCT00278395) and in combination therapy with 5 other drugs (NCT00324740, NCT2619253, NCT00324870). ${ }^{95,96}$ Panobinostat is a pan-HDACi used either alone or in combination with 2 drugs (NCT00550277, NCT01582009, NCT0 1005797). Romidepsin is an U.S. Food and Drug Administration (FDA)-approved potent inhibitor of HDAC1 and HDAC2 (NCT01638533, NCT00106613). Entinostat is another class I HDACi and has been tested in both monotherapy and together with 2 other compounds (NCT03552380, NCT03552380, NCT01038778, NCT03024437). ${ }^{97}$ AR-42 has been reported to have greater efficacy than SAHA, which was first used in $2005 .^{98}$ Belinostat, also called PDX101, exhibits antiproliferative and HDAC inhibitory capabilities at nanomolar concentrations against various human cancers. ${ }^{99}$ Although not all HDACi are cleared for RCCs therapy, many of them are FDA-approved for their therapeutic effects against many diseases. ${ }^{100}$

\section{CONCLUSIONS}

The role of epigenetic changes in the development and progression of RCC has become increasingly clear. However, despite the extensively knowledge of many epigenetic modifiers, further study of poorly characterized enzymes, especially in the context of cancer pathogenesis, is needed. Here, we have reviewed the evidence that epigenetic readers, writers, and erasers are candidate targets for the treatment of subtypes of RCCs. Taken together, this review provides innovative insights that targeting epigenetic regulators would be a good therapeutic strategy.

\section{CONFLICT OF INTEREST}

The authors claim no conflicts of interest. 


\section{ACKNOWLEDGMENTS}

This research was supported by Basic Science Research Program through the National Research Foundation of Korea (NRF) funded by the Ministry of Education (2018R1 D1A1B07051225).

\section{REFERENCES}

1. Ferlay J, Soerjomataram I, Dikshit R, Eser S, Mathers C, Rebelo $\mathrm{M}$, et al. Cancer incidence and mortality worldwide: sources, methods and major patterns in GLOBO CAN 2012. Int J Cancer 2015;136:E359-86.

2. Moch H. An overview of renal cell cancer: pathology and genetics. Semin Cancer Biol 2013;23:3-9.

3. Banks RE, Tirukonda P, Taylor C, Hornigold N, Astuti $\mathrm{D}$, Cohen D, et al. Genetic and epigenetic analysis of von Hippel-Lindau (VHL) gene alterations and relationship with clinical variables in sporadic renal cancer. Cancer Res 2006;66:2000-11.

4. Gnarra JR, Tory K, Weng Y, Schmidt L, Wei MH, Li $\mathrm{H}$, et al. Mutations of the VHL tumour suppressor gene in renal carcinoma. Nat Genet 1994;7:85-90.

5. Schmidt LS, Linehan WM. Genetic predisposition to kidney cancer. Semin Oncol 2016;43:566-74.

6. Dawson MA, Kouzarides T. Cancer epigenetics: from mechanism to therapy. Cell 2012;150:12-27.

7. de Cubas AA, Rathmell WK. Epigenetic modifiers: activities in renal cell carcinoma. Nat Rev Urol 2018;15:599614.

8. Biswas S, Rao CM. Epigenetic tools (The Writers, The Readers and The Erasers) and their implications in cancer therapy. Eur J Pharmacol 2018;837:8-24.

9. Kaneda M, Okano M, Hata K, Sado T, Tsujimoto N, Li E, et al. Essential role for de novo DNA methyltransferase Dnmt3a in paternal and maternal imprinting. Nature 2004;429:900-3.

10. Okano M, Bell DW, Haber DA, Li E. DNA methyltransferases Dnmt3a and Dnmt3b are essential for de novo methylation and mammalian development. Cell 1999; 99:247-57.

11. Li M, Wang Y, Song Y, Bu R, Yin B, Fei X, et al. Aberrant DNA methyltransferase 1 expression in clear cell renal cell carcinoma development and progression. Chin J Cancer Res 2014;26:371-81.

12. Fu RJ, He W, Wang XB, Li L, Zhao HB, Liu XY, et al. DNMT1-maintained hypermethylation of Kruppel-like factor 5 involves in the progression of clear cell renal cell carcinoma. Cell Death Dis 2017;8:e2952.
13. Lachance G, Uniacke J, Audas TE, Holterman CE, Franovic A, Payette J, et al. DNMT3a epigenetic program regulates the HIF-2alpha oxygen-sensing pathway and the cellular response to hypoxia. Proc Natl Acad Sci U S A 2014;111:7783-8.

14. Hon GC, Hawkins RD, Ren B. Predictive chromatin signatures in the mammalian genome. Hum Mol Genet 2009; 18:R195-201.

15. Zhang J, Zhang Q. VHL and hypoxia signaling: beyond HIF in cancer. Biomedicines 2018;6:35.

16. Qu Y, Liu L, Wang J, Xi W, Xia Y, Bai Q, et al. Dot11 expression predicts adverse postoperative prognosis of patients with clear-cell renal cell carcinoma. Oncotarget 2016;7:84775-84.

17. Li J, Kluiver J, Osinga J, Westers H, van Werkhoven MB, Seelen MA, et al. Functional studies on primary tubular epithelial cells indicate a tumor suppressor role of SETD2 in clear cell renal cell carcinoma. Neoplasia 2016;18:339-46.

18. Liu L, Guo R, Zhang X, Liang Y, Kong F, Wang J, et al. Loss of SETD2, but not H3K36me3, correlates with aggressive clinicopathological features of clear cell renal cell carcinoma patients. Biosci Trends 2017;11:214-20.

19. Kumar A, Kumari N, Sharma U, Ram S, Singh SK, Kakkar N, et al. Reduction in $\mathrm{H} 3 \mathrm{~K} 4 \mathrm{me}$ patterns due to aberrant expression of methyltransferases and demethylases in renal cell carcinoma: prognostic and therapeutic implications. Sci Rep 2019;9:8189.

20. Lee HW, Choe M. Expression of EZH2 in renal cell carcinoma as a novel prognostic marker. Pathol Int 2012;62: 735-41.

21. Adelaiye-Ogala R, Budka J, Damayanti NP, Arrington J, Ferris M, Hsu CC, et al. EZH2 modifies sunitinib resistance in renal cell carcinoma by kinome reprogramming. Cancer Res 2017;77:6651-66.

22. Wang Z, Zang C, Cui K, Schones DE, Barski A, Peng W, et al. Genome-wide mapping of HATs and HDACs reveals distinct functions in active and inactive genes. Cell 2009;138:1019-31.

23. Vempati RK, Jayani RS, Notani D, Sengupta A, Galande S, Haldar D. p300-mediated acetylation of histone H3 lysine 56 functions in DNA damage response in mammals. J Biol Chem 2010;285:28553-64.

24. Clemente-Ruiz M, Gonzalez-Prieto R, Prado F. Histone H3K56 acetylation, CAF1, and Rtt106 coordinate nucleosome assembly and stability of advancing replication forks. PLoS Genet 2011;7:e1002376.

25. Thomas T, Voss AK. The diverse biological roles of MYST histone acetyltransferase family proteins. Cell Cycle 2007;6:696-704.

26. Ogryzko VV, Schiltz RL, Russanova V, Howard BH, Nakatani Y. The transcriptional coactivators p300 and 
CBP are histone acetyltransferases. Cell 1996;87:953-9.

27. Feng X, Lu X, Man X, Zhou W, Jiang LQ, Knyazev P, et al. Overexpression of Csk-binding protein contributes to renal cell carcinogenesis. Oncogene 2009;28:3320-31.

28. Grabmaier K, MC AdW, Verhaegh GW, Schalken JA, Oosterwijk E. Strict regulation of CAIX(G250/MN) by HIF-1alpha in clear cell renal cell carcinoma. Oncogene 2004;23:5624-31.

29. Coral S, Sigalotti L, Altomonte M, Engelsberg A, Colizzi F, Cattarossi I, et al. 5-aza-2'-deoxycytidine-induced expression of functional cancer testis antigens in human renal cell carcinoma: immunotherapeutic implications. Clin Cancer Res 2002;8:2690-5.

30. Shang D, Han T, Xu X, Liu Y. Decitabine induces G2/M cell cycle arrest by suppressing p38/NF-kappaB signaling in human renal clear cell carcinoma. Int J Clin Exp Pathol 2015;8:11140-8.

31. Dunn J, Rao S. Epigenetics and immunotherapy: the current state of play. Mol Immunol 2017;87:227-39.

32. Gollob JA, Sciambi CJ, Peterson BL, Richmond T, Thoreson M, Moran K, et al. Phase I trial of sequential low-dose 5-aza-2'-deoxycytidine plus high-dose intravenous bolus interleukin-2 in patients with melanoma or renal cell carcinoma. Clin Cancer Res 2006;12:4619-27.

33. Faleiro I, Leao R, Binnie A, de Mello RA, Maia AT, Castelo-Branco P. Epigenetic therapy in urologic cancers: an update on clinical trials. Oncotarget 2017;8:12484-500.

34. Woo SM, Seo SU, Min KJ, Kwon TK. BIX-01294 sensitizes renal cancer Caki cells to TRAIL-induced apoptosis through downregulation of survivin expression and upregulation of DR5 expression. Cell Death Discov 2018;4:29.

35. Zagni C, Chiacchio U, Rescifina A. Histone methyltransferase inhibitors: novel epigenetic agents for cancer treatment. Curr Med Chem 2013;20:167-85.

36. Greiner D, Bonaldi T, Eskeland R, Roemer E, Imhof A. Identification of a specific inhibitor of the histone methyltransferase SU(VAR)3-9. Nat Chem Biol 2005;1:143-5.

37. Wagner T, Jung M. New lysine methyltransferase drug targets in cancer. Nat Biotechnol 2012;30:622-3.

38. Ramakrishnan S, Ellis L, Pili R. Histone modifications: implications in renal cell carcinoma. Epigenomics 2013; 5:453-62.

39. Datta K, Li J, Bhattacharya R, Gasparian L, Wang E, Mukhopadhyay D. Protein kinase $\mathrm{C}$ zeta transactivates hypoxia-inducible factor alpha by promoting its association with p300 in renal cancer. Cancer Res 2004;64:45662.

40. Zhang Y, Ng HH, Erdjument-Bromage H, Tempst P, Bird A, Reinberg D. Analysis of the NuRD subunits reveals a histone deacetylase core complex and a connection with DNA methylation. Genes Dev 1999;13:1924-35.

41. Hudson NO, Buck-Koehntop BA. Zinc finger readers of methylated DNA. Molecules 2018;23:2555.

42. Quenneville S, Verde G, Corsinotti A, Kapopoulou A, Jakobsson J, Offner S, et al. In embryonic stem cells, ZFP57/KAP1 recognize a methylated hexanucleotide to affect chromatin and DNA methylation of imprinting control regions. Mol Cell 2011;44:361-72.

43. Sharif J, Muto M, Takebayashi S, Suetake I, Iwamatsu A, Endo TA, et al. The SRA protein Np95 mediates epigenetic inheritance by recruiting Dnmt1 to methylated DNA. Nature 2007;450:908-12.

44. Spruijt CG, Gnerlich F, Smits AH, Pfaffeneder T, Jansen $\mathrm{PW}$, Bauer C, et al. Dynamic readers for 5-(hydroxy) methylcytosine and its oxidized derivatives. Cell 2013; 152:1146-59.

45. Ma J, Peng J, Mo R, Ma S, Wang J, Zang L, et al. Ubiquitin E3 ligase UHRF1 regulates p53 ubiquitination and $\mathrm{p} 53$-dependent cell apoptosis in clear cell renal cell carcinoma. Biochem Biophys Res Commun 2015;464: 147-53.

46. Musselman CA, Lalonde ME, Cote J, Kutateladze TG. Perceiving the epigenetic landscape through histone readers. Nat Struct Mol Biol 2012;19:1218-27.

47. Fragiadaki M, Zeidler MP. Ankyrin repeat and single KH domain 1 (ANKHD1) drives renal cancer cell proliferation via binding to and altering a subset of miRNAs. J Biol Chem 2018;293:9570-9.

48. Park JH, Jung M, Moon KC. The prognostic significance of nuclear expression of PHF2 and C/EBPalpha in clear cell renal cell carcinoma with consideration of adipogenic metabolic evolution. Oncotarget 2018;9:142-51.

49. Lange M, Kaynak B, Forster UB, Tonjes M, Fischer JJ, Grimm C, et al. Regulation of muscle development by DPF3, a novel histone acetylation and methylation reader of the BAF chromatin remodeling complex. Genes Dev 2008;22:2370-84.

50. Muller S, Filippakopoulos P, Knapp S. Bromodomains as therapeutic targets. Expert Rev Mol Med 2011;13:e29.

51. Hong SH, Eun JW, Choi SK, Shen Q, Choi WS, Han JW, et al. Epigenetic reader BRD4 inhibition as a therapeutic strategy to suppress E2F2-cell cycle regulation circuit in liver cancer. Oncotarget 2016;7:32628-40.

52. Wu X, Liu D, Gao X, Xie F, Tao D, Xiao X, et al. Inhibition of BRD4 suppresses cell proliferation and induces apoptosis in renal cell carcinoma. Cell Physiol Biochem 2017;41:1947-56.

53. Zhu H, Mao JH, Wang Y, Gu DH, Pan XD, Shan Y, et al. Dual inhibition of BRD4 and PI3K-AKT by SF2523 suppresses human renal cell carcinoma cell growth. Oncotarget 2017;8:98471-81.

54. Andrieu G, Belkina AC, Denis GV. Clinical trials for BET inhibitors run ahead of the science. Drug Discov Today Technol 2016;19:45-50. 
55. Sadakierska-Chudy A, Kostrzewa RM, Filip M. A comprehensive view of the epigenetic landscape part I: DNA methylation, passive and active DNA demethylation pathways and histone variants. Neurotox Res 2015;27:84-97.

56. Chen D, Maruschke M, Hakenberg O, Zimmermann W, Stief CG, Buchner A. TOP2A, HELLS, ATAD2, and TET3 are novel prognostic markers in renal cell carcinoma. Urology 265.e1-265.e7.

57. Long HK, Blackledge NP, Klose RJ. ZF-CxxC domain-containing proteins, $\mathrm{CpG}$ islands and the chromatin connection. Biochem Soc Trans 2013;41:727-40.

58. Tahiliani M, Koh KP, Shen Y, Pastor WA, Bandukwala $\mathrm{H}$, Brudno $\mathrm{Y}$, et al. Conversion of 5-methylcytosine to 5-hydroxymethylcytosine in mammalian DNA by MLL partner TET1. Science 2009;324:930-5.

59. Zhou H, Tang K, Liu H, Zeng J, Li H, Yan L, et al. Regulatory network of two tumor-suppressive noncoding RNAs interferes with the growth and metastasis of renal cell carcinoma. Mol Ther Nucleic Acids 2019;16:554-65.

60. Mullighan CG. TET2 mutations in myelodysplasia and myeloid malignancies. Nat Genet 2009;41:766-7.

61. Solary E, Bernard OA, Tefferi A, Fuks F, Vainchenker W. The ten-eleven translocation-2 (TET2) gene in hematopoiesis and hematopoietic diseases. Leukemia 2014;28: 485-96.

62. Elgendy M, Fusco JP, Segura V, Lozano MD, Minucci $\mathrm{S}$, Echeveste JI, et al. Identification of mutations associated with acquired resistance to sunitinib in renal cell cancer. Int J Cancer 2019;145:1991-2001.

63. Gu TP, Guo F, Yang H, Wu HP, Xu GF, Liu W, et al. The role of Tet3 DNA dioxygenase in epigenetic reprogramming by oocytes. Nature 2011;477:606-10.

64. Shi Y, Lan F, Matson C, Mulligan P, Whetstine JR, Cole $\mathrm{PA}$, et al. Histone demethylation mediated by the nuclear amine oxidase homolog LSD1. Cell 2004;119:941-53.

65. Karytinos A, Forneris F, Profumo A, Ciossani G, Battaglioli E, Binda C, et al. A novel mammalian flavindependent histone demethylase. J Biol Chem 2009;284: 17775-82.

66. Ciccone DN, Su H, Hevi S, Gay F, Lei H, Bajko J, et al. KDM1B is a histone $\mathrm{H} 3 \mathrm{~K} 4$ demethylase required to establish maternal genomic imprints. Nature 2009;461: 415-8.

67. Cloos PA, Christensen J, Agger K, Helin K. Erasing the methyl mark: histone demethylases at the center of cellular differentiation and disease. Genes Dev 2008;22: 1115-40.

68. Black JC, Van Rechem C, Whetstine JR. Histone lysine methylation dynamics: establishment, regulation, and biological impact. Mol Cell 2012;48:491-507.

69. Guo X, Zhang Q. The emerging role of histone demethylases in renal cell carcinoma. J Kidney Cancer VHL
2017;4:1-5.

70. Yamada D, Kobayashi S, Yamamoto H, Tomimaru Y, Noda T, Uemura M, et al. Role of the hypoxia-related gene, JMJD1A, in hepatocellular carcinoma: clinical impact on recurrence after hepatic resection. Ann Surg Oncol 2012;19 Suppl 3:S355-64.

71. Yang H, Liu Z, Yuan C, Zhao Y, Wang L, Hu J, et al. Elevated JMJD1A is a novel predictor for prognosis and a potential therapeutic target for gastric cancer. Int J Clin Exp Pathol 2015;8:11092-9.

72. Wang Q, Wei J, Su P, Gao P. Histone demethylase JARID1C promotes breast cancer metastasis cells via down regulating BRMS1 expression. Biochem Biophys Res Commun 2015;464:659-66.

73. Dalgliesh GL, Furge K, Greenman C, Chen L, Bignell G, Butler A, et al. Systematic sequencing of renal carcinoma reveals inactivation of histone modifying genes. Nature 2010;463:360-3.

74. Gossage L, Murtaza M, Slatter AF, Lichtenstein CP, Warren A, Haynes B, et al. Clinical and pathological impact of VHL, PBRM1, BAP1, SETD2, KDM6A, and JARID1c in clear cell renal cell carcinoma. Genes Chromosomes Cancer 2014;53:38-51.

75. Shen Y, Guo X, Wang Y, Qiu W, Chang Y, Zhang A, et al. Expression and significance of histone H3K27 demethylases in renal cell carcinoma. BMC Cancer 2012; 12:470.

76. Wang XL, Li CL, Yang LH, Jiang ZM, Gui YT, Cai ZM. Clinical significance of high expression with UTX in renal cell carcinoma. Beijing Da Xue Xue Bao Yi Xue Ban 2014;46:926-30.

77. Guenther MG, Barak O, Lazar MA. The SMRT and $\mathrm{N}-\mathrm{CoR}$ corepressors are activating cofactors for histone deacetylase 3. Mol Cell Biol 2001;21:6091-101.

78. Zhang J, Kalkum M, Chait BT, Roeder RG. The $\mathrm{N}-\mathrm{CoR}-\mathrm{HDAC} 3$ nuclear receptor corepressor complex inhibits the JNK pathway through the integral subunit GPS2. Mol Cell 2002;9:611-23.

79. Wen YD, Perissi V, Staszewski LM, Yang WM, Krones A, Glass CK, et al. The histone deacetylase-3 complex contains nuclear receptor corepressors. Proc Natl Acad Sci U S A 2000;97:7202-7.

80. Li J, Wang J, Wang J, Nawaz Z, Liu JM, Qin J, et al. Both corepressor proteins SMRT and N-CoR exist in large protein complexes containing HDAC3. EMBO J 2000;19:4342-50.

81. Gregoretti IV, Lee YM, Goodson HV. Molecular evolution of the histone deacetylase family: functional implications of phylogenetic analysis. J Mol Biol 2004;338: 17-31.

82. Kiweler N, Brill B, Wirth M, Breuksch I, Laguna T, Dietrich $\mathrm{C}$, et al. The histone deacetylases HDAC1 and 
HDAC2 are required for the growth and survival of renal carcinoma cells. Arch Toxicol 2018;92:2227-43.

83. Cha TL, Chuang MJ, Wu ST, Sun GH, Chang SY, Yu DS, et al. Dual degradation of aurora A and B kinases by the histone deacetylase inhibitor LBH589 induces G2-M arrest and apoptosis of renal cancer cells. Clin Cancer Res 2009;15:840-50.

84. Lahm A, Paolini C, Pallaoro M, Nardi MC, Jones P, Neddermann $\mathrm{P}$, et al. Unraveling the hidden catalytic activity of vertebrate class IIa histone deacetylases. Proc Natl Acad Sci U S A 2007;104:17335-40.

85. Sparrow DB, Miska EA, Langley E, Reynaud-Deonauth $\mathrm{S}$, Kotecha S, Towers N, et al. MEF-2 function is modified by a novel co-repressor, MITR. EMBO J 1999;18: 5085-98.

86. Zhu Q, Yu L, Qin Z, Chen L, Hu H, Zheng X, et al. Regulation of OCT2 transcriptional repression by histone acetylation in renal cell carcinoma. Epigenetics 2019;14: 791-803.

87. Yang XJ, Gregoire S. Class II histone deacetylases: from sequence to function, regulation, and clinical implication. Mol Cell Biol 2005;25:2873-84.

88. Fan W, Huang J, Xiao H. Histone deacetylase 10 suppresses proliferation and invasion by inhibiting the phosphorylation of beta-catenin and serves as an independent prognostic factor for human clear cell renal cell carcinoma. Int J Clin Exp Med 2015;8:3734-42.

89. Zhang Z, Cao Y, Zhao W, Guo L, Liu W. HDAC6 serves as a biomarker for the prognosis of patients with renal cell carcinoma. Cancer Biomark 2017;19:169-75.

90. Gao L, Cueto MA, Asselbergs F, Atadja P. Cloning and functional characterization of HDAC11, a novel member of the human histone deacetylase family. J Biol Chem 2002;277:25748-55.

91. Jeh SU, Park JJ, Lee JS, Kim DC, Do J, Lee SW, et al. Differential expression of the sirtuin family in renal cell carcinoma: aspects of carcinogenesis and prognostic significance. Urol Oncol 2017;35:675.e9-675.e15.
92. Finley LW, Carracedo A, Lee J, Souza A, Egia A, Zhang J, et al. SIRT3 opposes reprogramming of cancer cell metabolism through HIF1alpha destabilization. Cancer Cell 2011;19:416-28.

93. Zhang CZ, Liu L, Cai M, Pan Y, Fu J, Cao Y, et al. Low SIRT3 expression correlates with poor differentiation and unfavorable prognosis in primary hepatocellular carcinoma. PLoS One 2012;7:e51703.

94. Xiao K, Jiang J, Wang W, Cao S, Zhu L, Zeng H, et al. Sirt3 is a tumor suppressor in lung adenocarcinoma cells. Oncol Rep 2013;30:1323-8.

95. Dasari A, Gore L, Messersmith WA, Diab S, Jimeno A, Weekes $\mathrm{CD}$, et al. A phase I study of sorafenib and vorinostat in patients with advanced solid tumors with expanded cohorts in renal cell carcinoma and non-small cell lung cancer. Invest New Drugs 2013;31:115-25.

96. Zibelman M, Wong YN, Devarajan K, Malizzia L, Corrigan A, Olszanski AJ, et al. Phase I study of the mTOR inhibitor ridaforolimus and the HDAC inhibitor vorinostat in advanced renal cell carcinoma and other solid tumors. Invest New Drugs 2015;33:1040-7.

97. Shen L, Ciesielski M, Ramakrishnan S, Miles KM, Ellis $\mathrm{L}$, Sotomayor P, et al. Class I histone deacetylase inhibitor entinostat suppresses regulatory $\mathrm{T}$ cells and enhances immunotherapies in renal and prostate cancer models. PLoS One 2012;7:e30815.

98. Lu Q, Wang DS, Chen CS, Hu YD, Chen CS. Structurebased optimization of phenylbutyrate-derived histone deacetylase inhibitors. J Med Chem 2005;48:5530-5.

99. Plumb JA, Finn PW, Williams RJ, Bandara MJ, Romero MR, Watkins CJ, et al. Pharmacodynamic response and inhibition of growth of human tumor xenografts by the novel histone deacetylase inhibitor PXD101. Mol Cancer Ther 2003;2:721-8.

100. Eckschlager T, Plch J, Stiborova M, Hrabeta J. Histone deacetylase inhibitors as anticancer drugs. Int J Mol Sci 2017; $18: 1414$. 